\title{
TANDEM TERMINAL ION SOURCE
}

\author{
G.C. HARPER, C.E. LINDER, A.W. MYERS, T.D. VAN WECHEL \\ Nuclear Physics Laboratory, Box 354290, University of Washington, \\ Seattle, WA 98195
}

The terminal ion source (TIS) was used in several experiments during this reporting period, all for the ${ }^{7} \mathrm{Be}(\mathrm{p}, \gamma)^{8} \mathrm{~B}$ experiment. Most of the runs used ${ }^{1} \mathrm{H}^{+}$at terminal voltages from $0.3 \mathrm{MV}$ to $1.5 \mathrm{MV}$. One of the runs used ${ }^{2} \mathrm{H}^{+}$ at terminal voltage of $1.4 \mathrm{MV}$. The other run used ${ }^{4} \mathrm{He}^{+}$at a terminal voltage of $1.37 \mathrm{MV}$. The list of experiments run with the TIS to date is given in table 1 below.

The tank was opened four times for unscheduled source repairs. On one occasion the tank was opened to replace the einzel lens power supply which had failed. The $10 \mathrm{kV}$ unit was replaced with a $15 \mathrm{kV}$ unit. The second time the tank was opened to repair the extractor supply which was damaged by a tank spark. On the next occasion the tank was opened to replace a source canal which had sputtered away. Finally, the tank was opened to replace the discharge bottle which had been coated with aluminum sputtered from the exit canal.

Development for this year included design, fabrication, and testing of a toroidal electrostatic deflector. The toroidal deflector was designed to have optical properties as similar as possible to those of a double focussing magnet. When tested it was found that the deflector had focussing power that was unbalanced in the vertical and horizontal planes or had second order effects that were more significant than expected. Transport of an ion beam from the deflector was difficult at all energies tested. We plan to do further tests using unbalanced electrode voltages after careful modeling with an electrostatics design program.

Further developments included design, construction and testing of a new permanent magnet for the deflection of ${ }^{1} \mathrm{H}^{+}$and ${ }^{2} \mathrm{H}^{+}$. The new magnet for $13.5 \mathrm{keV}{ }^{1} \mathrm{H}^{+}$has a field of $1.18 \mathrm{kG}$ as opposed to the $1.91 \mathrm{kG}$ magnet used for $11.6 \mathrm{keV}^{3} \mathrm{He}^{+}$. Proton output on the high energy cup is about $30 \mu$ amps from $800 \mathrm{keV}$ to $2.5 \mathrm{MeV}$ and drops fairly rapidly above and below those energies. A $5 \mu \mathrm{amp}$ beam at $193 \mathrm{keV}$ has been observed on the high energy cup and analyzed with $3 \mu$ amps appearing on the image cup. A set of pole pieces was also constructed for this magnet to deflect $14.0 \mathrm{keV}{ }^{2} \mathrm{H}^{+}$at a field of $1.65 \mathrm{kG}$.

An additional development was the alteration of the ${ }^{3} \mathrm{He}^{+}$magnet to deflect ${ }^{4} \mathrm{He}^{+}$by replacing the pole pieces with narrower ones. The $1.91 \mathrm{kG}$ magnet used for $11.6 \mathrm{keV}{ }^{3} \mathrm{He}^{+}$has been increased to $2.23 \mathrm{kG}$ for use with 


\section{DISCLAIMER}

This report was prepared as an account of work sponsored by an agency of the United States Government. Neither the United States Government nor any agency thereof, nor any of their employees, make any warranty, express or implied, or assumes any legal liability or responsibility for the accuracy, completeness, or usefulness of any information, apparatus, product, or process disclosed, or represents that its use would not infringe privately owned rights. Reference herein to any specific commercial product, process, or service by trade name, trademark, manufacturer, or otherwise does not necessarily constitute or imply its endorsement, recommendation, or favoring by the United States Government or any agency thereof. The views and opinions of authors expressed herein do not necessarily state or reflect those of the United States Government or any agency thereof. 
the pulses from our low energy buncher which makes phase-locking the buncher extremely difficult.

We examined the grid and found no visual indication of damage. We changed the grid anyway as was advised by other members of the accelerator community. This produced no noticable change. We examined the tube from the outside and noticed no discoloration.

We examined the tube through the viewports on the tank and noticed glow discharges occurring in four regions. These emitted a faint blue glow and varied in intensity with time. We were unable to determine if they varied in intensity with x-ray output. The first three regions were close to the grounded end of tube \#1 but past the low-gradient region where we use half value resistors. The fourth region was at the downstream end of tube \#1 and extended about three tube sections.

We installed an aluminum boat attached to a nylon fish line that we ran from the low energy end to the midsection. The purpose of the boat was to short various tube planes. The boat spanned seven accelerator tube planes. When located over planes 80 to 86 the x-ray emission dropped by over an order of magnitude. We were able to transport heavy ion beams in this configuration and at the same time phase-lock our low energy buncher. We have installed half-value resistors between planes $82-83,83-84$, and $84-85$. We have replaced the larger boat with one that spans only one gap. We hope to narrow our search to as small a region as possible and install half-value resistors in the offending gaps and those that are $180^{\circ}$ away on the spiral tube.

\section{LHe refrigerator}

For the first time in 14 years of operation the cryogenics system experienced a significant ice blockage in the refrigerator delivery tube (RDT) which connects the helium refrigerator to the dewar. The one inch diameter inner tube of this vacuum-jacketed coaxial RDT carries mixed liquid and vapor helium to the dewar for phase separation, and it became partially blocked over the last year. The two inch diameter annular vapor-return was not compromised. The effect of this blockage was to reduce cooling capacity with our wet engine, though J-T cooling capacity was little affected. The blockage might have been air ice or water ice. Approximately $100 \mathrm{cc}$ of water was pumped from the helium passages of the warmed refrigerator. An unmeasured but similar quantity of water was purged from the warmed RDT and dewar region. On 11 October the refrigerator was cold and idling, the RDT and dewar are still warm, and the cryostats are at liquid nitrogen temperature. Plans are to have the LINAC cold by 1 November. 


\begin{tabular}{|c|c|c|c|}
\hline ION & $\begin{array}{c}\text { ENERGY RANGE } \\
(\mathrm{kev})\end{array}$ & EXPERIMENT & $\begin{array}{c}\text { BEAM CURRENT } \\
(\mu \mathrm{amps})\end{array}$ \\
\hline \hline${ }^{1} \mathrm{H}^{+}$ & $300-1400$ & ${ }^{7} \mathrm{Be}(\mathrm{p}, \gamma)$ & $10-20$ \\
\hline${ }^{2} \mathrm{H}^{+}$ & 770,1000 & ${ }^{7} \mathrm{Li}(\mathrm{d}, \mathrm{p})$ & $15-18$ \\
\hline${ }^{3} \mathrm{He}^{+}$ & 5500 & ${ }^{6} \mathrm{Li}\left({ }^{3} \mathrm{He}, \mathrm{n}\right)$ & 28 \\
\hline${ }^{4} \mathrm{He}^{+}$ & 1370 & ${ }^{7} \mathrm{Be}(\alpha, \gamma)$ & 12 \\
\hline
\end{tabular}

Table 1: Table of Ion Species and TIS Experiments

$10.2 \mathrm{keV}{ }^{4} \mathrm{He}^{+}$. The ${ }^{4} \mathrm{He}^{+}$is a very stable beam at $1.37 \mathrm{MeV}$ with $12 \mu$ amps observed on the high energy cup and $11.5 \mu$ amps analyzed. So far, it has been used successfully down to $450 \mathrm{keV}$.

We continue to use 0.5 inch diameter chrome-plated steel ball bearings inserted between the anti-corona rings of the column to short out various planes of the beam tube. We have found this to be an extremely fast way to alter the gradient for optimum beam transmission at these low energies. Future plans for terminal ion source use are to develop a gradient which can be successfully used with a high intensity, very low energy (100 keV to $300 \mathrm{keV})$ ion beam. A new gradient has been designed but not yet tested. 